\title{
A meta-analysis of transcriptome datasets characterizes malignant transformation from melanocytes and nevi to melanoma
}

\author{
DANIEL ORTEGA-BERNAL ${ }^{1}$, CLAUDIA H. GONZÁLEZ-DE LA ROSA ${ }^{1}$, ELENA ARECHAGA-OCAMPO ${ }^{1}$, \\ MIGUEL ANGEL ALVAREZ-AVITIA ${ }^{2}$, NORA SOBREVILLA MORENO ${ }^{2}$ and CLAUDIA RANGEL-ESCAREÑO ${ }^{3}$ \\ ${ }^{1}$ Natural Sciences Department, Universidad Autónoma Metropolitana, Mexico City 05300; \\ ${ }^{2}$ Medical Oncology Department, Instituto Nacional de Cancerología, Mexico City $14080 ;{ }^{3}$ Computational and \\ Integrative Genomics Laboratory, Instituto Nacional de Medicina Genómica, Mexico City 14610, Mexico
}

Received October 13, 2017; Accepted March 12, 2018

DOI: $10.3892 / \mathrm{ol} .2018 .8861$

\begin{abstract}
Melanoma represents one of the most aggressive malignancies and has a high tendency to metastasize. The present study aims to investigate the molecular mechanisms of two pathways to cancer transformation with the purpose of identifying potential biomarkers. Our approach is based on a meta-analysis of gene expression profiling contrasting two scenarios: A model that describes a transformation pathway from melanocyte to melanoma and a second model where transformation occurs through an intermediary nevus. Data consists of three independent, publicly available microarray datasets from the Gene Expression Omnibus (GEO) database comprising samples from melanocytes, nevi and melanoma. The present analysis identified 808 differentially expressed genes (528 upregulated and 360 downregulated) in melanoma compared with nevi, and 2,331 differentially expressed genes (946 upregulated and 1,385 downregulated) in melanoma compared with melanocytes. Further analysis narrowed down this list, since 682 differentially expressed genes were found in both models (417 upregulated and 265 downregulated). Enrichment analysis identified relevant dysregulated pathways. This article also presented a discussion on significant genes including ADAM like decysin 1, neudesin neurotrophic factor, $M M P 19$, apolipoprotein L6, $C-X-C$ motif chemokine ligand $(C X C L) 8$, basic, immunoglobulin-like variable motif containing and CXCL16. These are of particular interest
\end{abstract}

Correspondence to: Dr Claudia Rangel-Escareño, Computational and Integrative Genomics Laboratory, Instituto Nacional de Medicina Genómica, Periférico Sur 4809, Arenal Tepepan, Mexico City 14610, Mexico

E-mail: crangel@inmegen.gob.mx

Dr Claudia H. González-De la Rosa, Natural Sciences Department, Universidad Autónoma Metropolitana, Cuajimalpa. Av. Vasco de Quiroga 4871, Santa Fe Cuajimalpa, Mexico City 05300, Mexico E-mail: cgonzalez@correo.cua.uam.mx

Key words: melanoma, melanocyte, nevus, transcriptome, meta-analysis, biomarker because they encode secreted proteins hence represent potential blood biomarkers for the early detection of malignant transformation in both scenarios. Cytotoxic T-lymphocyte associated protein 4 , an important therapeutic target in melanoma treatment, was also upregulated in both comparisons indicating a potential involvement in immune tolerance, not only at advanced stages but also during the early transformation to melanoma. The results of the present study may provide a research direction for studying the mechanisms underlying the development of melanoma, depending on its origin.

\section{Introduction}

Cutaneous melanoma is the most type of aggressive skin cancer due to its ability to rapidly metastasize and its radioand chemotherapy resistance. Therefore, cutaneous melanoma is associated with a high mortality rate if it is not treated at early stages (1). Furthermore, the frequency of cutaneous melanoma has increased fourfold worldwide over the last 30 years (2). Melanoma may develop directly from transformed melanocytes or through a stepwise progression after first forming a benign nevus $(3,4)$. Findings show that both paths result from mutations in genes of the mitogen-activated protein (MAP) kinase pathway and subsequent changes in other genes that affect regulatory pathways, including p53 (5) and phosphoinositide 3-kinase/AKT signaling pathways (6).

Melanocytes, which generate melanin in mammals (7), are uniformly distributed in the skin. These cells may form nevi, which are melanocyte clusters in specific areas. In most cases, nevi are caused by $B R A F$ mutations or mutations in genes of the RAS family $(8,9)$. These mutations constitutively activate the MAP kinase pathway, which is involved in cell division. The resultant nevus consists of melanocytes with limited growth that are in a 'senescence-like' state (10). Additional mutations in genes, such as cyclin dependent kinase inhibitor 2A (11) or phosphatase and tensin homolog (5), are known to be required for a cell in a nevus to develop into melanoma. This mechanism is observed in $\sim 30 \%$ of melanoma cases (12).

Mutations may alter gene expression. Therefore, a variety of studies have addressed the classification and staging of melanoma through transcriptome analysis such as microarray technology. Some of those gene expression microarray studies 
on cancer transformation compare melanoma biopsies with skin as 'normal' sample or with nevus $(13,14)$. However, strategies based on a meta-analysis that include a collection of such studies have proven to be useful identifying genes and pathways not only involved in the transformation but also in describing disease progression through gene profiling (15).

Melanoma is considered one of the most aggressive malignancies, and as such, patients with advanced melanoma tend to have a poor prognosis (1), and there is an urgent need to identify biomarkers. The work presented here proposes a list of biomarkers associated with malignant transformation in melanoma based on a transcriptome meta-analysis. Our approach to reveal these biomarkers was to compare the gene expression profiles of primary melanocyte cultures, nevus samples, and stages I, II, and III of melanoma samples according to the tumor-node metastasis (TNM) staging system, seventh edition (1) [primary tumor (T), regional lymph nodes $(\mathrm{N})$ and distant metastasis (M)]. Microarrays downloaded from Gene Expression Omnibus repository (GEO) (16) were carefully selected. The present study focused on two paths: Malignant transformation directly from melanocytes and transformation through an intermediary nevus. By analyzing data carefully collected from different studies, the aim of the present study was to identify novel mechanisms underlying the molecular changes observed during malignant transformation. Outcomes of the study involved the identification of new pathways and biomarkers with potential application in clinical practice.

\section{Materials and methods}

Data extraction. Gene expression data obtained from a collection of different microarrays studies conducted prior to March 2015 were used for the present study. All data are publicly available through the GEO (16), which incorporated samples from melanocytes [accession no., GSE38312 (17), n=5], nevi [accession no., GSE53223 (18), n=5], and melanoma stage I, II and III tumors [accession no., GSE15605 (19), n=40].

Inclusion criteria for microarray samples. The inclusion criteria for microarray samples are as follows: i) Human biopsies; ii) cutaneous melanoma; iii) samples corresponding to primary melanoma sites; iv) samples classified as stages I, II or III according to TNM; v) nevus samples taken from biopsy; vi) melanocyte samples from primary cultures.

Exclusion criteria. The exclusion criteria are as follows: i) Samples from patients already under treatment; ii) metastatic samples; iii) sub-stage IIIC samples equivalent to in-transit metastasis due to an already intermediate path between the primary site and the invasive stage; iv) cell lines; v) melanoma in situ; vi) dysplastic nevi; vii) nevi in patients with a family history of melanoma (as these patients have a higher risk for melanoma). The selection of data files used in the present study is depicted in Fig. 1.

Quality assessment and data extraction. All statistical analyses were conducted using the statistical software R (20) and a variety of libraries from Bioconductor (21). Raw data were background corrected using Robust Multiarray Average (22) and were normalized with quantile normalization (23) using the Affy package. As all microarrays involved were processed at raw level, no further correction for batch effect was required. Any batch effect was addressed during the normalization steps, which ultimately aims at making all samples comparable and at removing systematic variation.

Statistical analysis. Differential expression was analyzed using linear models and the Limma library (24). Two main summary statistics were used to classify genes as being differentially expressed: Fold-change on a $\log 2$ scale and B-statistic, which is the Bayesian equivalent to an adjusted P-value. According to the design of the present study, the analysis focused on 3 comparisons: i) Nevi vs. melanocytes; ii) melanoma vs. nevi and iii) melanoma vs. melanocytes. Target genes were selected based on a log fold-change $>1$ for upregulation and $\log$ fold-change $<-1$ for downregulation. Statistical significance was defined as a B-statistic $>3$, which corresponds to a $95.3 \%$ confidence level. Particular interest was focused on the gene set at the intersection of two comparisons: Melanoma vs. nevi and melanoma vs. melanocytes; as these genes represent possible biomarkers for melanoma transformation.

Unsupervised hierarchical clustering. Results from two comparisons of interest were used: Melanoma vs. nevi and melanoma vs. melanocytes. The two lists of differentially expressed genes were further reduced using Median Absolute Deviation (25) to capture the most variable set of genes. Using an unsupervised hierarchical clustering approach with the R-library ggplots (26), clustering patterns of genes (a) at the intersection of the two lists and (b) disjoint genes were searched for.

Gene Set Enrichment Analysis (GSEA). GSEA was used to determine whether an a priori defined set of genes derived from annotation or pathway databases exhibited statistically significant differential expression between two models. The analysis was conducted using the Ingenuity ${ }^{\circledR}$ Pathway Analysis tool (IPA ${ }^{\circledR}$, Qiagen, Inc., Valencia, CA, USA). The following thresholds were used for gene selection: $-\log (P$-value $)>1.3$ $(P$-value $<0.05)$ and a $\mid z$-score $\mid>1 . \mathrm{P}<0.05$ and a $\mid z$-scorel $>2$ were used for analysis of biological processes.

\section{Results}

Eligible studies for the meta-analysis. The initial search yielded 315 datasets. Next, by screening the full characteristics and the quality control, 312 datasets were excluded. Therefore, only 3 datasets from GEO were selected, with samples from melanocytes [GSE38312 (17), n=5], nevi [GSE53223 (18), $\mathrm{n}=5$ ], and melanoma stages I, II and III [GSE15605 (19), $\mathrm{n}=40]$. Primary melanomas at stage IV and metastatic melanoma samples were excluded to simplify the analysis of gene expression changes that occur during the early transformation of non-cancerous cells (melanocytes or nevi) to melanoma cells. Samples that are clinically identified to have metastatic capacity according to staging were not included. By the same reasoning, sub-stage IIIC samples equivalent to in-transit metastasis were excluded. A flow chart of the selection process is illustrated in Fig. 1. The samples of each microarray in the meta-analysis are described in Table I. 
Table I. Description of studies included in the meta-analysis.

\begin{tabular}{|c|c|c|c|c|c|c|}
\hline $\begin{array}{l}\text { Accession } \\
\text { no. }\end{array}$ & $\begin{array}{c}\text { Year of } \\
\text { publication }\end{array}$ & Summary & $\begin{array}{c}\text { Total } \\
\text { samples }\end{array}$ & $\begin{array}{c}\text { Type of } \\
\text { sample selected }\end{array}$ & $\begin{array}{c}\text { Number of } \\
\text { sample selected }\end{array}$ & (Refs.) \\
\hline GSE38312 & 2014 & $\begin{array}{l}\text { Early-passage }(<10 \text { passages }) \\
\text { cultures of melanoma cells from } \\
\text { metastatic lymph node lesions and } \\
\text { normal adult melanocytes explanted } \\
\text { in parallel from the adjacent, } \\
\text { non-involved skin of } 5 \text { patients }\end{array}$ & 10 & Melanocytes & 5 & (17) \\
\hline GSE53223 & 2016 & $\begin{array}{l}\text { Excisional biopsies consisting of } \\
5 \text { common melanocytic nevi, } \\
7 \text { dysplastic nevi and } 6 \text { normal skin }\end{array}$ & 18 & Nevi & 5 & (18) \\
\hline GSE15605 & 2013 & $\begin{array}{l}\text { Excisional biopsies consisting of } \\
46 \text { primary melanomas, } 12 \text { melanoma } \\
\text { metastases and } 16 \text { normal skin }\end{array}$ & 74 & $\begin{array}{l}\text { Melanoma stages I, } \\
\text { II and III }\end{array}$ & 40 & (19) \\
\hline
\end{tabular}

Differential expression. Differentially expressed genes were identified in three comparisons: i) Nevi vs. melanocytes (2,492 genes); ii) melanoma vs. nevi (1,881 genes); and iii) melanoma vs. melanocytes (4,112 genes). The proportion of genes that are exclusive to each comparison and those that overlap is indicated in the Venn diagram in Fig. 2A. These comparisons explain the transformation from melanocytes to melanoma through two paths. One path represents a direct transformation process, with 1,385 downregulated and 946 upregulated genes (which is exclusive to this comparison), and another path develops from an intermediary nevus with 360 downregulated and 528 upregulated genes (which is also exclusive to this comparison) (Fig. 2B). It is important to note that even though differentially expressed genes obtained from the comparison of nevi vs. melanocytes were of no direct use, they were required to filter out those genes at the different intersections. For instance, the melanoma vs. nevi comparison with 1,881 differentially expressed genes comprises only 888 unique genes, because 311 genes were also present in the progression from melanocytes to nevi. Therefore, these genes must be excluded from the list, since they represent false positives in terms of explaining malignant transformation. Genes at the intersection of melanoma vs. nevi with melanoma vs. melanocytes ( 682 genes) were analyzed as potential biomarkers, as described below, since these are associated with melanoma development either directly from melanocytes or from nevi.

In a search for a minimum gene set that could discriminate between the 3 groups (melanocytes, nevi and melanoma), the top 50 genes following median absolute deviation were selected. This procedure was followed by an unsupervised hierarchical clustering analysis. The results from this analysis are illustrated in Fig. 2C, which represents a heat map of the 50 most discriminating genes associated with cancer that is based on the comparisons: Melanoma vs. melanocytes and melanoma vs. nevi (2,331 and 888 genes, respectively; Fig. 2A). These top 50 genes were able to identify a transition profile from melanocytes to melanoma using nevi as intermediates. The clustering patterns for the genes at the intersection of melanoma vs. melanocytes and melanoma vs. nevi (682 genes, Fig. 2A) are represented by the heat map in Fig. 2D. The 50 genes appearing

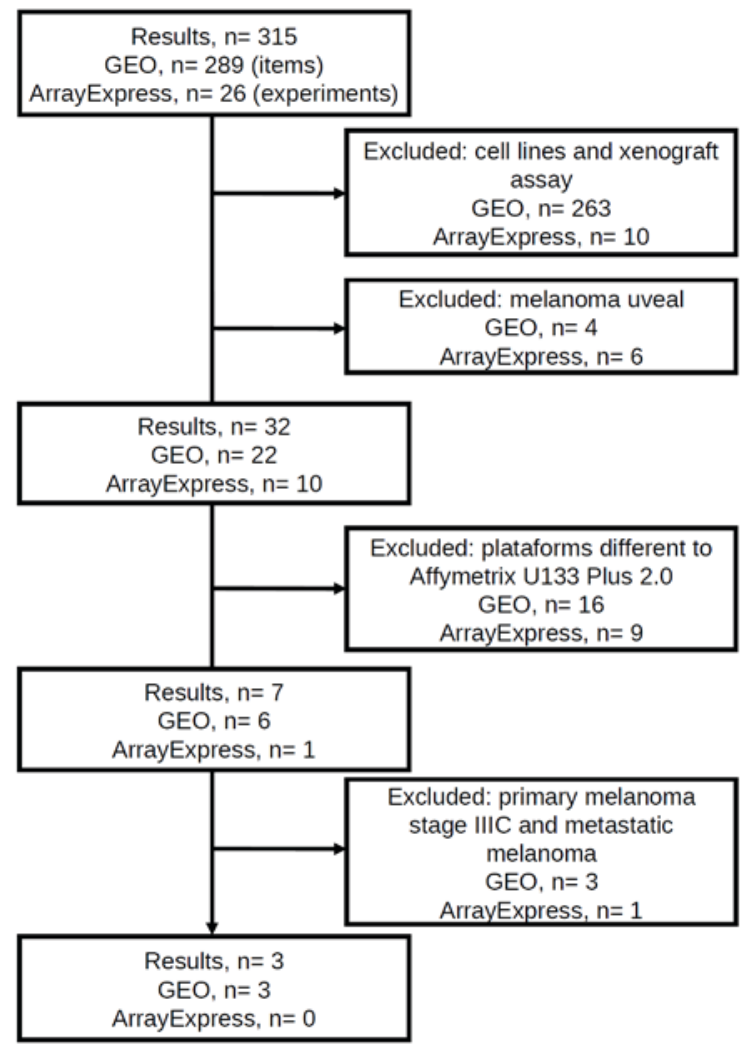

Figure 1. Selection of gene expression datasets for meta-analysis. The following terms were used for the initial search: 'Homo sapiens', 'expression transcription profiling', 'array assay' and 'melanoma'. GEO, Gene Expression Omnibus.

in both comparisons were non-randomly partitioned into two major groups and clearly describe malignant transformation, as melanocytes and nevi were clearly separated from melanoma.

Use of gene interaction enrichment and network analysis to identify dysregulated pathways. To interpret gene expression data based on the functional annotation of the differentially expressed genes and their association with biological processes or molecular functions, an enrichment analysis of genes that 
A

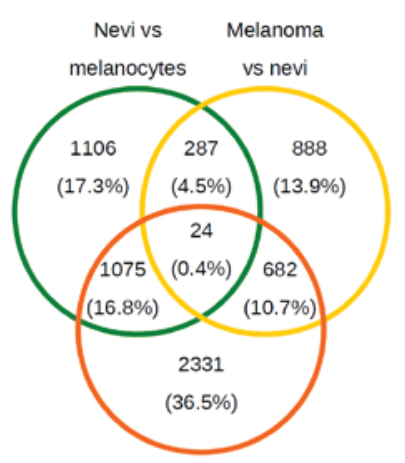

Melanoma vs

melanocytes

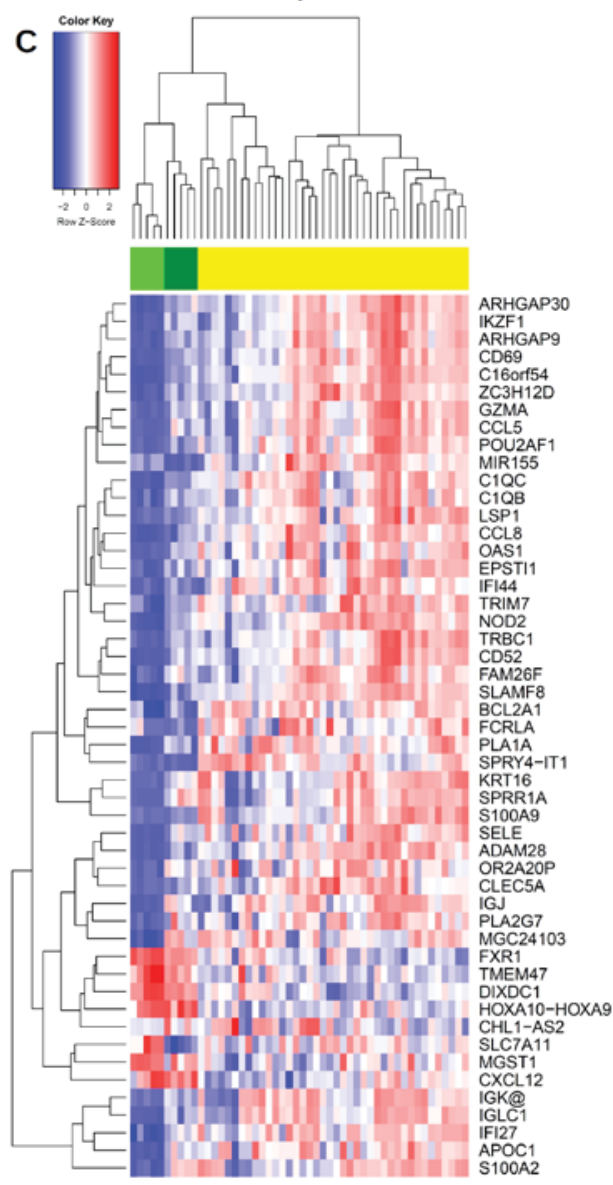

B

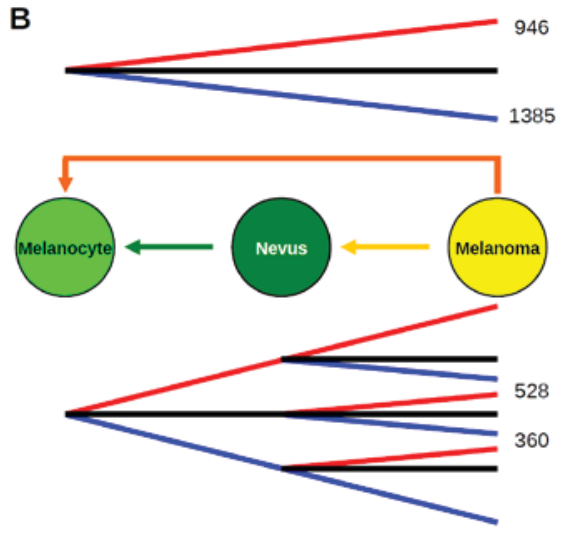

D

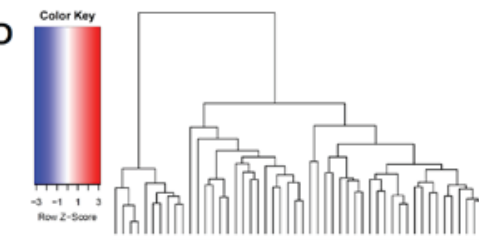

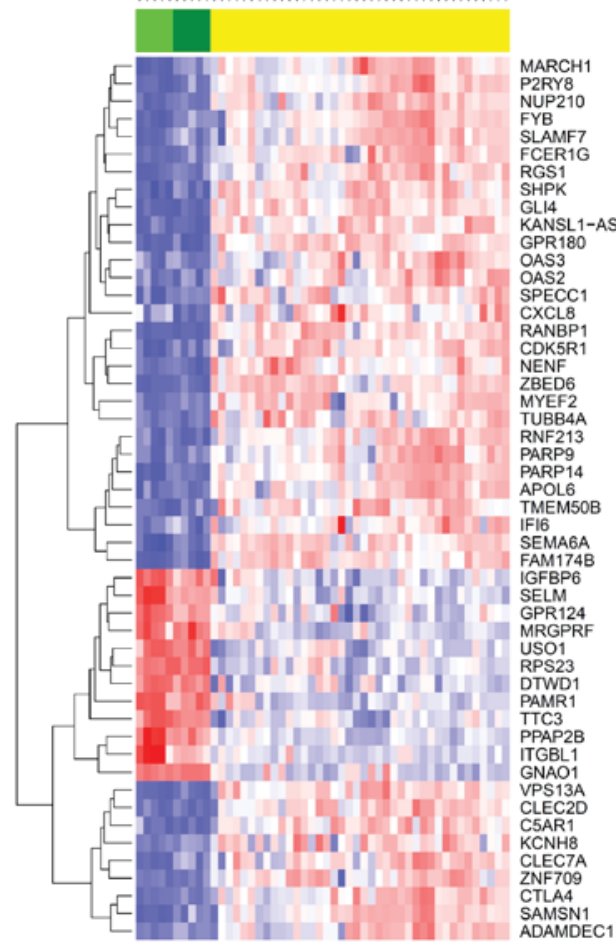

Figure 2. Differentially expressed genes. (A) Venn diagram of the differential expression results for the comparisons among nevi, melanocytes and melanoma Green circle, the number of genes with different expression levels between nevi and melanocytes. Yellow circle, the number of genes with different expression levels between melanoma vs. nevi. Orange circle, the number of genes with different expression levels between melanoma vs. melanocytes. Colors in the Venn diagram match the color of each comparison shown in B. (B) Diagram illustrating how the expression of genes change as they follow a path that ultimately results in melanoma. Blue and red lines indicate downregulation and upregulation, respectively. Black lines indicate no change. Genes in samples that developed melanoma directly from melanocytes are shown in the top panel, and the number of genes that was used to assess changes is indicated. Genes in samples in which melanoma developed from an intermediary nevus are shown at the bottom, and the number of genes that was used to assess changes from nevus to melanoma are indicated. As indicated in this diagram, 3 possible paths were identified in melanoma samples that had directly transformed from melanocytes, and 9 possible paths were identified in melanoma samples that transformed via an intermediary nevus. A given gene may have 10 possible transformation paths at the transcriptome level when removing the 2 paths that did not show changes in expression. (C) Hierarchical clustering based on the 50 most discriminating genes that are unique to each comparison: Melanoma vs. melanocytes (2,331 genes) and melanoma vs. nevi ( 888 genes). Melanocyte (light green label), nevus (dark green label) and melanoma (yellow label) samples fell into two major groups. (D) Hierarchical clustering based on the 50 most discriminating genes that are common to each comparison: Melanoma vs. melanocytes and melanoma vs. nevi (682 genes). Melanocyte (light green label), nevus (dark green label) and melanoma (yellow label) samples fell into two major groups.

resulted from the malignant transformation was performed through nevus analysis as well as to the direct transformation obtained from the melanocyte analysis. The results are indicated in Fig. 3.
Malignant transformation via nevi. Malignant transformation through an intermediary nevus was characterized by a total of 1,881 differentially expressed genes (comprising 737 downregulated and 1,144 upregulated genes). Only the 888 unique 
A
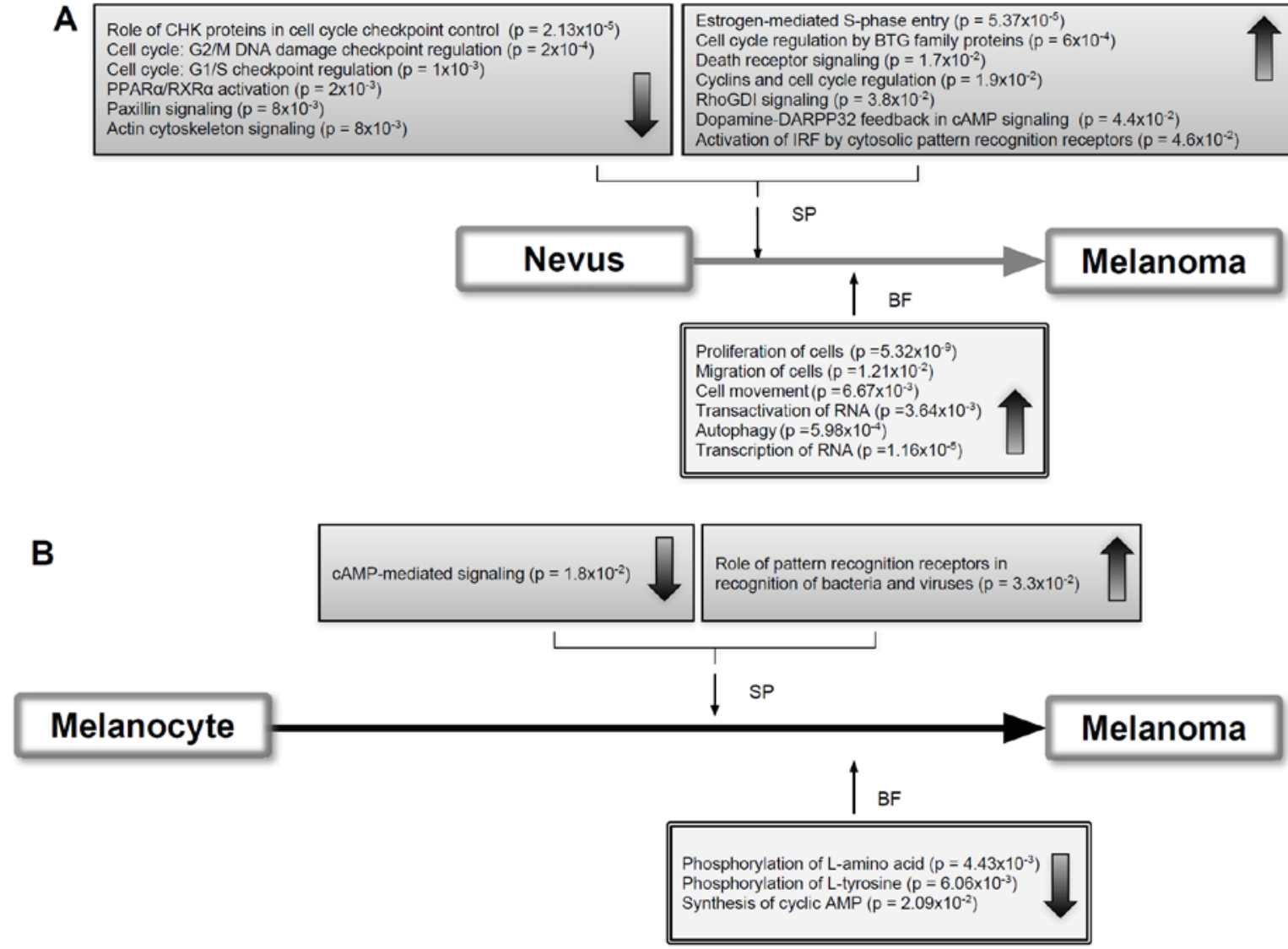

Figure 3. Gene Set Enrichment Analysis. (A) Signaling pathways and biological functions that are involved in cancer transformation via a nevus; three of the pathways exhibiting decreased activity are involved in cell cycle checkpoints. Conversely, a number of the activated pathways are associated with cell cycle progression. (B) Signaling pathways and biological functions that are involved in cancer transformation from melanocytes. The samples exhibited decreased cAMP synthesis, which is consistent with the decreased activity of this pathway. Numbers in parenthesis represent statistical significance (P-values) as assigned by Ingenuity ${ }^{\circledR}$ Pathway Analysis. BF, biological functions; PPAR $\alpha$, peroxisome proliferator activated receptor $\alpha$; SP, signaling pathways.

genes based on the Venn diagram in Fig. 2A were used to explain malignant transformation via nevi. An enrichment analysis of these genes identified 13 dysregulated pathways; 6 of these (mostly associated with cell cycle control) exhibited decreased activity, and 7 (associated with cell cycle progression) exhibited increased activity. In addition, 6 biological functions were activated, and 4 of these were associated with the hallmarks of cancer: Proliferation, migration, cell movement and autophagy (Fig. 3A).

Direct transformation from melanocytes. The model based on direct transformation from melanocytes included 4,112 differentially expressed genes (2,310 downregulated and 1,802 upregulated). However, only the 2,331 genes unique to malignant transformation from melanocytes were used to perform the gene enrichment analysis for signaling pathways and biological processes. The results show that specifically cAMP-mediated signaling was the only pathway to exhibit decreased activity. By contrast, pattern recognition receptors (C1QA, C1QB, C1QC, CCL5 and IFNA4) were upregulated. Biological functions associated with the phosphorylation of L-amino acids and cAMP synthesis exhibited decreased activity (Fig. 3B).

Potential biomarkers. To identify transformation biomarkers in melanoma, the present study focused on the genes at the intersection of melanoma vs. melanocytes and melanoma vs. nevi comparisons (682 genes, Fig. 2A). The analysis began with a classification of these genes into intracellular and extracellular biomarkers with the aim of capturing effects at both the transcriptional and protein levels. Genes that appeared upregulated in both comparisons and whose product was a secreted protein were selected as potential secreted biomarkers (22 genes) and are listed in Table II. Previously characterized cancer biomarkers, cytokines $\mathrm{C}-\mathrm{X}-\mathrm{C}$ motif chemokine ligand (CXCL)8 and CXCL16, were included in this group. Another biomarker, that was included in the list, matrix metallopeptidase 19 (MMP19), is inhibited by the drug Marimastat.

There were more intracellular biomarkers in the list, which might be used as cancer biomarkers in biopsies. In total, there were 48 genes comprising 24 downregulated and 24 upregulated genes. Literature reviews on each gene consistently identify these biomarkers in human pathology $(9,47-78)$. The list is shown in Table III.

\section{Discussion}

In this meta-analysis, which included 3 independent datasets with 50 gene expression microarrays from GEO, the gene expression of two molecular pathways for melanoma were compared. One pathway transforms melanocytes directly to melanoma and another pathway that passes through an intermediate state 


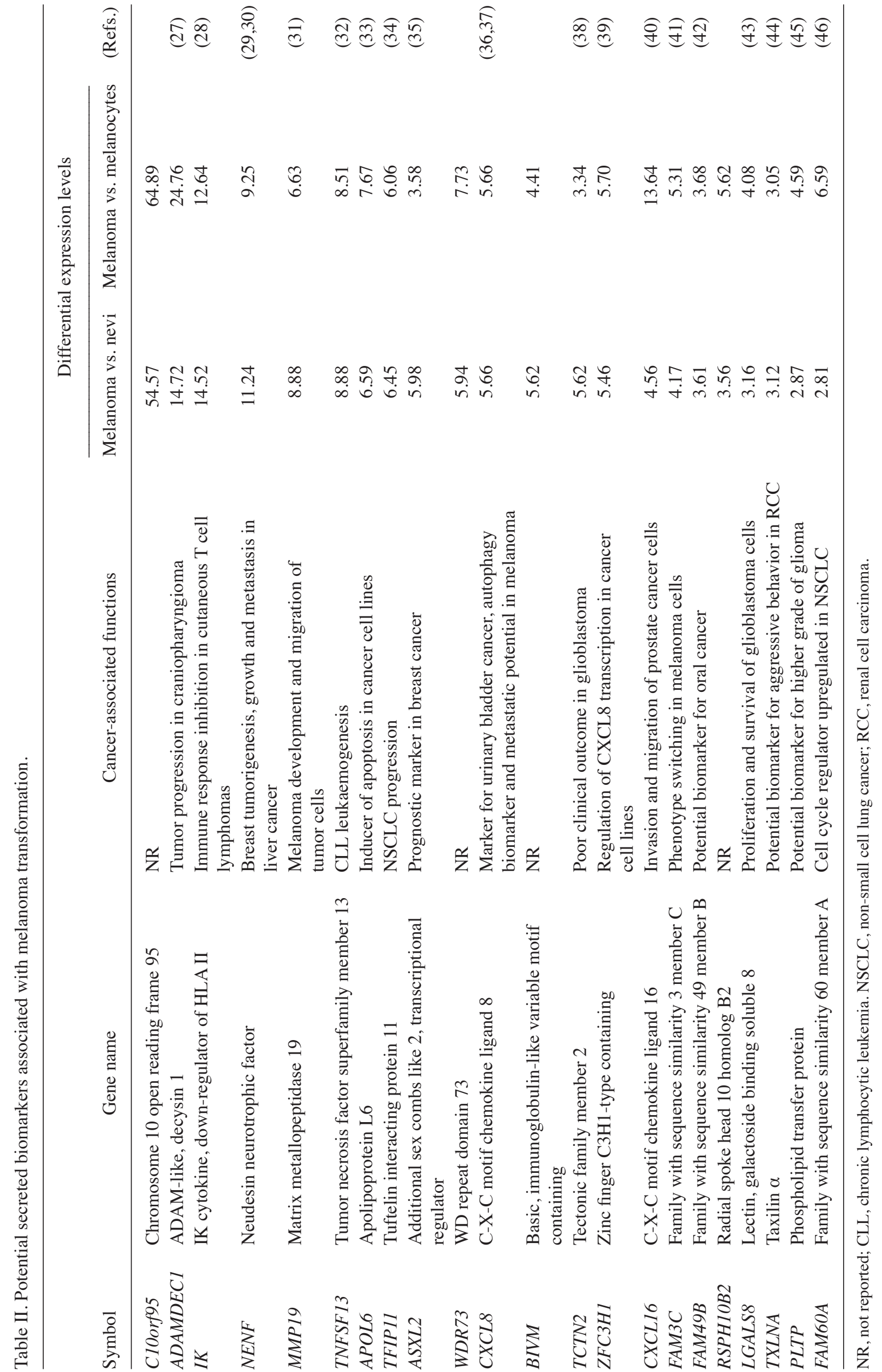


(nevi). Data were collected based on samples taken from melanocytes, nevi, which were taken as an intermediary stage, and melanoma stages I, II and III.

A number of previous studies compared samples in the radial growth phase vs. samples in the vertical growth phase (79), whereas other studies analyzed melanoma but without considering clinical stage (13). A number of studies also used cell lines, nevi or skin as 'normal' samples (14). In the present study, the selection of melanocytes as the 'normal' sample and the selection of biopsies obtained only from primary melanomas (stages I, II or III) are major strengths of our work.

The results show clear differences between the two pathways of melanoma development according to the cell of origin. The transformation through nevi model shows that the list of differentially expressed genes are associated with biological functions that are consistent with the development and progression of cancer, including proliferation, migration, cell movement (80) and autophagy (81). In addition, three pathways associated with cell cycle control that exhibited declined activity were identified: Cell cycle checkpoint control involving CHK proteins, DNA damage checkpoint regulation at $\mathrm{G} 2 / \mathrm{M}$ and regulation of $\mathrm{G} 1 / \mathrm{S}$ checkpoint. Another pathway exhibiting a decreased activity was peroxisome proliferator activated receptor $\alpha / \mathrm{RXR} \alpha$ activation, which has been reported to exert anti-proliferative effects on melanocytes and melanoma $(82,83)$. By contrast, pathways with increased activity are cyclins and cell cycle regulation, and estrogen-mediated S-phase entry, which promote cell cycle progression. These pathways are consistent with malignant transformation.

Shepelin et al (15) recently identified 25 metabolic pathways and 19 signaling pathways as being implicated in the transformation to melanoma using skin samples as the starting stage and nevi as an intermediary stage. An increased function of pathways was reported, including hypoxia inducible factor 1 $\alpha$ subunit, ATM (DNA repair), putrescine biosynthesis II, and breast and ovarian cancer susceptibility protein 1 . A decreased activity was reported for biosynthesis of histamine, eumelanin and allopregnanolone and degradation of valine. However, these results were not consistent with our findings.

Melanocytes represent only a minority in the cell population within the basilar epidermis since the melanocyte to keratinocyte ratio is 1:5 and they are neural crest-derived cells (84). The present analysis included transcriptomes from primary cultures of melanocytes whilst previous studies have used skin as 'normal' samples $(13,14)$. On the other hand, continuous cell lines have already evaded senescence control as they have increased cell proliferation rate. The authors consider that finite cultures of melanocytes represent a better biological model since these cells are manipulated in vitro for shorter periods ( $<10$ passages) (17). We also consider that this is the main reason why the results showed a large number of differentially expressed genes. Enrichment analysis only showed that the decreased activity of the cAMP-mediated signaling pathway was significantly associated with transformation. Previous studies report that the cAMP signaling pathway inhibits the development of melanoma (85); this finding contrasts with another report that claims that this pathway promotes the growth of melanoma (86).
So far, lactate dehydrogenase (LDH) has been useful as a secretory biomarker in the tumor-node metastasis (TNM) staging of melanoma. High levels of LDH are associated with poor prognosis at advanced stages of the disease (M1c, stage IV) (1). In addition to the use of LDH as a biomarker, the identification of more molecules as good biomarkers of melanoma is necessary to identify not only stage IV disease but also early stages of the disease and high-risk populations. The present meta-analysis identified 22 potential secreted biomarkers, of which CXCL16 and CXCL8 have been previously reported as biomarkers in patients with Crohn's disease (87) and in several diseases, including urinary bladder cancer, non-Hodgkin's lymphoma and pulmonary infections (88). A literature review indicated that CXCL8 is linked to autophagy in melanoma cell lines (35) and has been reported in metastasis (37). Here, CXCL8 appeared in the top 50 of modulated genes (Fig. 3C). Another potential secreted biomarker, $M M P 19$, has been identified in progression and invasiveness events in melanoma (31). To examine the basal abundance of these proteins, the Protein Atlas (89) was searched, and the search identified the levels of $C X C L 8$, CXCL16, MMP19, basic, immunoglobulin-like variable motif containing $(B I V M)$ and family with sequence similarity 60 member A (FAM60A) to be low in other tissues. BIVM is a poorly studied protein, whereas FAM60A is a cell cycle regulator that is reportedly upregulated in non-small cell lung cancer (46). These results are interesting because low abundance of CXCL8, CXCL16, MMP19, BIVM and FAM60A in other tissues might correspond to low serum concentrations in healthy individuals. Therefore, if these proteins were abundant in melanoma, this would facilitate their detection in the serum as biomarkers. Other genes that encode secreted proteins include ADAM like decysin 1 ( $A D A M D E C 1)$, neudesin neurotrophic factor (NENF) and apolipoprotein L6 (APOL6), which are included in the list of top 50 modulated genes (Fig. 3D). In brief, $A D A M D E C 1$ encodes a protein with metalloendopeptidase activity and has been identified as a biomarker of recurrence and poor prognosis in craniopharyngioma (28). NENF has been reported as an oncogene in breast cancer (29) and as a potential therapeutic target in liver cancer (30). APOL6 encodes an apolipoprotein BCL-2 homolog that acts as an apoptosis inducer (33).

Several tentative intracellular biomarkers were also identified in the analysis, 24 of which were downregulated and 24 of which were upregulated. Among previously reported genes, it was observed that tumor protein P53 (TP53) is upregulated in melanoma compared with melanocytes and nevi. The upregulation of TP53 in melanoma has been reported, albeit with abnormal function and regulation (67). Other findings include $M D M 2$, which was upregulated in melanoma compared with melanocytes, and MDM4, which was upregulated in melanoma compared with nevi. Both MDM2 and MDM4 are inhibitors of p53. Similarly, the downregulation of various inhibitors of cyclin-dependent kinases [cyclin dependent kinase inhibitor $(C D K N) 1 A$, $C D K N 1 C, C D K N 2 C$ and $C D K N 2 D$ ], which interact with p53 or inhibit the activity of various cyclin-dependent kinases, was observed. It was also observed that $\mathrm{C}-\mathrm{X}-\mathrm{C}$ motif chemokine receptor 4 (CXCR4), a chemokine receptor involved in metastasis, was upregulated. $C X C R 4$ has a prognostic value 


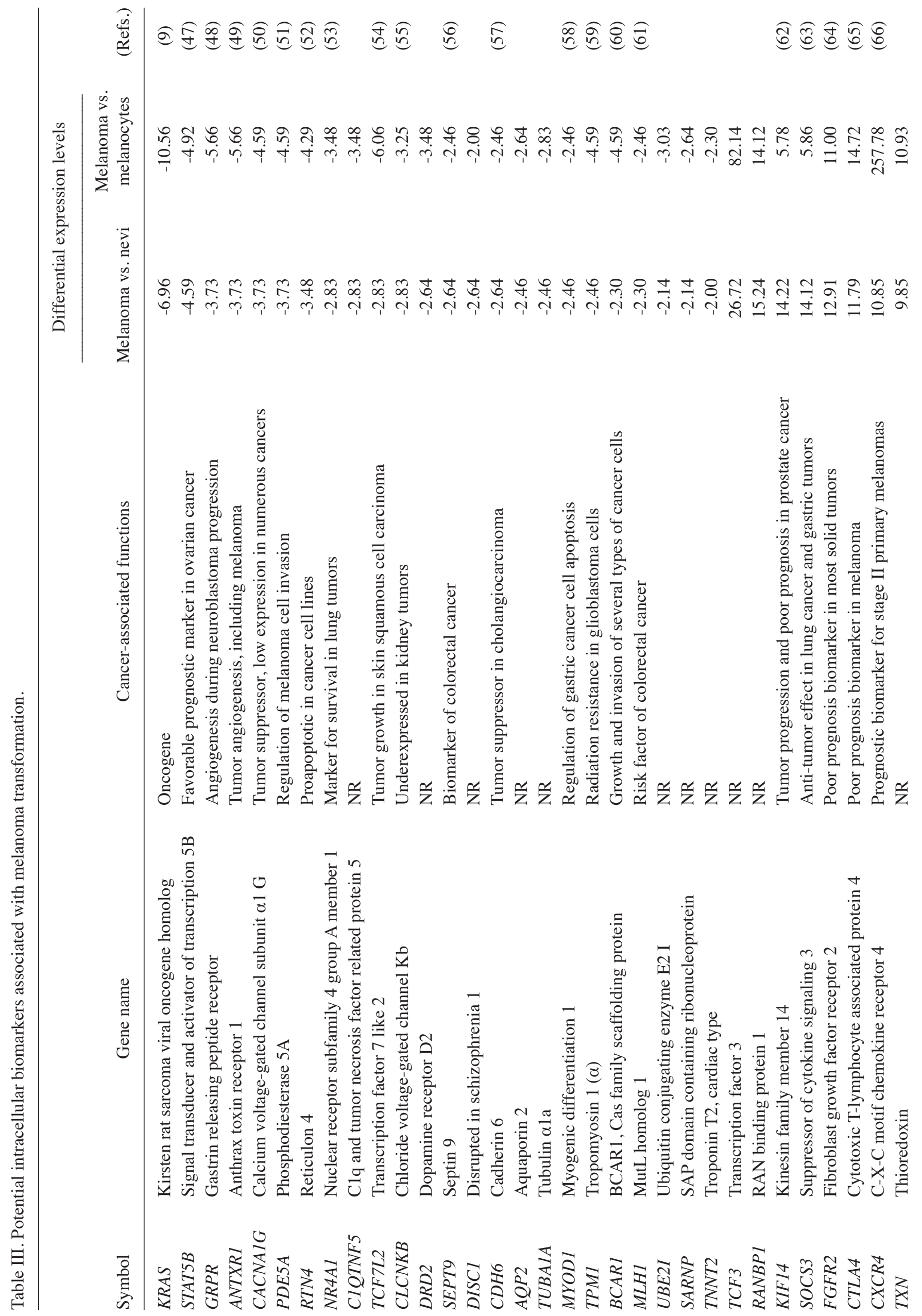




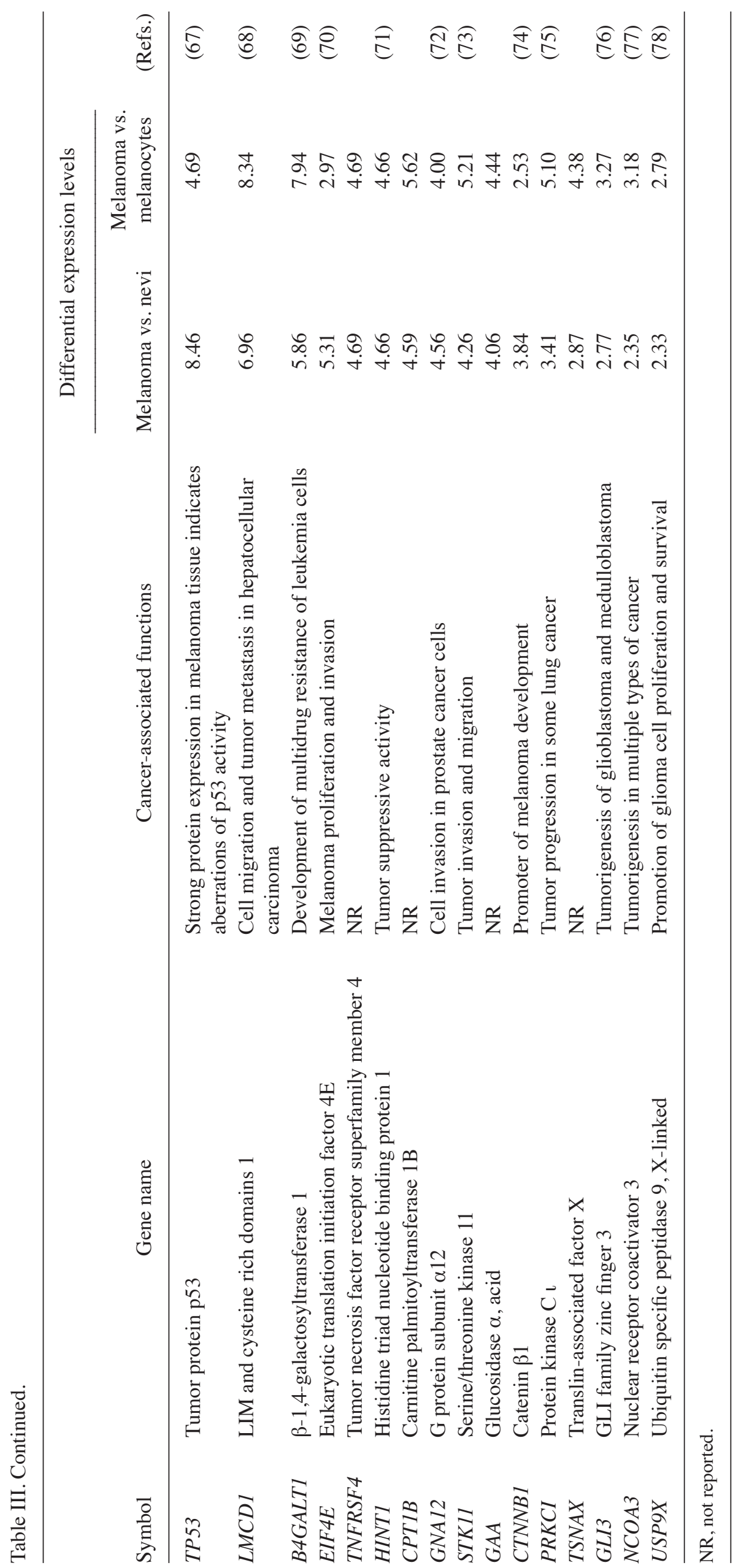


in stage II melanoma (66). Another potential intracellular biomarker is cytotoxic T-lymphocyte associated protein 4 (CTLA4), which is upregulated during the transformation to melanoma, and in the list of the top 50 modulated genes (Fig. 2D). This protein has gained increasing attention in recent years as the target of ipilimumab, the first immune checkpoint inhibitor approved to treat unresectable melanoma (90). CTLA-4, a CD28 homologue, was originally described as a glycoprotein that is membrane bound on activated T-cells and regulatory $\mathrm{T}$ (Treg)-cells and which has a high binding affinity with the molecule B7, which is primarily expressed on antigen-presenting cells (APCs) (91). The expression and function of CTLA4 have been previously observed for various types of non-T cells, including several malignant solid tumors such as melanoma (92). This suggests that CTLA-4 might be involved in controlling functions other than the widely described T-cell response inactivation (93). In the tumor microenvironment, it is well documented that CTLA4 is upregulated in activated T cells, therefore providing inhibitory co-stimulation; it may lead to apoptosis and/or a state of immunologic anergy. Treg cells, which constitutively express high levels of CTLA4, also regulate effector T cells by downregulating B7 in APCs, leading to the induction and maintenance of T-cell tolerance by reducing CD28 co-stimulation (94). In addition, B7 ligation by CTLA-4 on Treg cells induces immunosuppressive APC by enhancing the indoleamine 2,3-dioxygenase tryptophan catabolic enzyme cascade, thereby preventing T-cell activation by depriving T cells of tryptophan. Proapoptotic tryptophan catabolites can also exert strong immunosuppression and indirectly suppress effector $\mathrm{T}$ cell response by favoring differentiation of Treg cells, which in turn would repeat CTLA-4 interactions (95). For all those reasons, CTLA-4 is considered the 'leader' of the immune checkpoint. At present, the physiological role of CTLA4 expression in melanoma cells remains unknown, but a recent study reported that high levels of CTLA4 in tumor cells in melanoma patients were associated with poor clinical outcomes (65). Other studies have demonstrated that the upregulation of CTLA4 is a factor predictive of poor prognosis in nasopharyngeal (96), esophageal (97) and breast carcinomas (98).

In this context, it is worth noting that even soluble forms of CTLA-4 (99) and cell transfectants that upregulate membrane-anchored CTLA-4 (100) can signal through B7 in a similar manner to CTLA-4 on T cells and resemble the same tolerogenic effects. Indeed, breast cancer cells that express CTLA-4 are involved in this novel tumor-evading mechanism (93). A number of types of cancer cells express CTLA4 (92), so it is likely that in order to evade immune surveillance the same mechanism is used by melanoma cells.

We would also like to address some limitations of the present study. First of all, there are a small number of studies with TNM staging and therefore, the number of included microarrays was not as large as one would expect in a meta-analysis. However, statistical power might be undermined by a large collection of heterogeneous samples than it could be for a small but well characterized set of samples. Secondly, the data from melanocytes comes from a monoculture setting. It is well known that keratinocytes significantly impact the mRNA expression profile of melanocytes; therefore, the profile may not be the same for melanocytes in situ. Primary culture is the best resembling natural tissue but is largely heterogeneous. We believe that this is the main reason why transition from melanocyte to melanoma showed only 2 dysregulated signaling pathways based on the enrichment analysis of genes identified as differentially expressed. Lastly, there are technical biases that are due to the fact that the samples were processed in different labs, by different people and at different times. This was well addressed during the normalization process and batch effect was removed by pre-processing all samples at raw level.

In conclusion, the present study provided a list of differentially expressed genes, molecular pathways and potential biomarkers associated with melanoma for direct transformation from melanocytes and from nevus as intermediary stage. The data suggest that molecular mechanisms underlying these two pathways of transformation into melanoma are different; however, both pathways share molecular changes that might be important for the identification of early biomarkers that are specific to melanoma. Overall, testing for the high-level expression of CXCL8, CXCL16, MMP19, BIVM, FAM60A, $A D A M D E C 1, N E N F$ and $A P O L 6$, whose products are secreted proteins, might detect malignant transformation at its earliest presence, a requisite for improving preventive interventions and reducing cancer incidence. Other intracellular biomarkers found might have prognostic or therapeutic target potential. The present meta-analysis found in silico evidence that upregulation of CTLA4 may have a role in the transformation towards melanoma, possibly related to immune tolerance.

\section{Acknowledgements}

Not applicable.

\section{Funding}

The present study was supported by grants from Consejo Nacional de Ciencia y Tecnología (CONACYT), which was award to Claudia H. González-De la Rosa (grant no. 181534) and Consejo Nacional de Ciencia y Tecnología (CONACYT), which was awarded to Daniel Ortega Bernal (fellowship no. 372614).

\section{Availability of data and materials}

The datasets analyzed during the current study are available in the Gene Expression Omnibus (GEO) database repository, https://www.ncbi.nlm.nih.gov/geo/ query/acc.cgi?acc=GSE38312, https://www.ncbi.nlm.nih. gov/geo/query/acc.cgi?acc=GSE53223 and https://www.ncbi. nlm.nih.gov/geo/query/acc.cgi?acc=GSE15605.

\section{Authors' contributions}

DO, CG and CR were responsible for the conception and design of the study. DO, EA and CR developed themethodology, and DO was responsible for the acquisition of data. DO, CG, EA, MA, NS and CR were involved in the analysis and interpretation of data. DO, CG, EA, MA, NS and CR wrote, reviewed 
and revised the manuscript. CG and CR were responsible for the supervision of the study.

\section{Ethics approval and consent to participate}

Not applicable.

\section{Consent for publication}

Not applicable.

\section{Competing interests}

The authors declare that they have no competing interests.

\section{References}

1. Balch CM, Gershenwald JE, Soong SJ, Thompson JF, Atkins MB Byrd DR, Buzaid AC, Cochran AJ, Coit DG, Ding S, et al: Final version of 2009 AJCC melanoma staging and classification. J Clin Oncol 27: 6199-6206, 2009.

2. Bray F, Jemal A, Grey N, Ferlay J and Forman D: Global cancer transitions according to the human development index (2008-2030): A population-based study. Lancet Oncol 13 790-801, 2012.

3. Shain AH and Bastian BC: From melanocytes to melanomas. Nat Rev Cancer 16: 345-358, 2016.

4. Shitara D, Nascimento MM, Puig S, Yamada S, Enokihara MM, Michalany $\mathrm{N}$ and Bagatin E: Nevus-associated melanomas: Clinicopathologic features. Am J Clin Pathol 142: 485-491, 2014

5. Bardeesy N, Bastian BC, Hezel A, Pinkel D, DePinho RA and Chin L: Dual inactivation of RB and p53 pathways in RAS-induced melanomas. Mol Cell Biol 21: 2144-2153, 2001.

6. Vredeveld LC, Possik PA, Smit MA, Meissl K, Michaloglou C, Horlings HM, Ajouaou A, Kortman PC, Dankort D McMahon M, et al: Abrogation of BRAFV600E-induced senescence by PI3K pathway activation contributes to melanomagenesis. Genes Dev 26: 1055-1069, 2012.

7. Costin GE and Hearing VJ: Human skin pigmentation: Melanocytes modulate skin color in response to stress. FASEB J 21: 976-994, 2007.

8. Pollock PM, Harper UL, Hansen KS, Yudt LM, Stark M, Robbins CM, Moses TY, Hostetter G, Wagner U, Kakareka J, et al: High frequency of BRAF mutations in nevi. Nat Genet 33: 19-20, 2003.

9. Poynter JN, Elder JT, Fullen DR, Nair RP, Soengas MS, Johnson TM, Redman B, Thomas NE and Gruber SB: BRAF and NRAS mutations in melanoma and melanocytic nevi. Melanoma Res 16: 267-273, 2006.

10. Michaloglou C, Vredeveld LC, Soengas MS, Denoyelle C, Kuilman T, van der Horst CM, Majoor DM, Shay JW, Mooi WJ and Peeper DS: BRAFE600-associated senescence-like cel cycle arrest of human naevi. Nature 436: 720-724, 2005.

11. Johmura Y, Shimada M, Misaki T, Naiki-Ito A, Miyoshi H, Motoyama N, Ohtani N, Hara E, Nakamura M, Morita A, et al: Necessary and sufficient role for a mitosis skip in senescence induction. Mol Cell 55: 73-84, 2014

12. Lin WM, Luo S, Muzikansky A, Lobo AZ, Tanabe KK, Sober AJ, Cosimi AB, Tsao H and Duncan LM: Outcome of patients with de novo versus nevus-associated melanoma. J Am Acad Dermatol 72: 54-58, 2015.

13. Smith AP, Hoek K and Becker D: Whole-genome expression profiling of the melanoma progression pathway reveals marked molecular differences between nevi/melanoma in situ and advanced-stage melanomas. Cancer Biol Ther 4: 1018-1029, 2005.

14. Talantov D, Mazumder A, Yu JX, Briggs T, Jiang Y, Backus J, Atkins D and Wang Y: Novel genes associated with malignant melanoma but not benign melanocytic lesions. Clin Cancer Res 11: 7234-7242, 2005.

15. Shepelin D, Korzinkin M, Vanyushina A, Aliper A, Borisov N, Vasilov R, Zhukov N, Sokov D, Prassolov V, Gaifullin N, et al: Molecular pathway activation features linked with transition from normal skin to primary and metastatic melanomas in human. Oncotarget 7: 656-670, 2016.
16. Barrett T, Wilhite SE, Ledoux P, Evangelista C, Kim IF, Tomashevsky M, Marshall KA, Phillippy KH, Sherman PM, Holko M, et al: NCBI GEO: Archive for functional genomics data sets-update. Nucleic Acids Res 41: D991-D995, 2013.

17. Tremante E, Ginebri A, Lo Monaco E, Benassi B, Frascione P, Grammatico $\mathrm{P}$, Cappellacci $\mathrm{S}$, Catricalà $\mathrm{C}$, Arcelli D, Natali PG, et al: A melanoma immune response signature including Human Leukocyte Antigen-E. Pigment Cell Melanoma Res 27: 103-112, 2014.

18. Mitsui H, Kiecker F, Shemer A, Cannizzaro MV, Wang CQ, Gulati N, Ohmatsu H, Shah KR, Gilleaudeau P, Sullivan-Whalen M, et al: Discrimination of dysplastic nevi from common melanocytic nevi by cellular and molecular criteria. J Invest Dermatol 136: 2030-2040, 2016.

19. Raskin L, Fullen DR, Giordano TJ, Thomas DG, Frohm ML, Cha KB, Ahn J, Mukherjee B, Johnson TM and Gruber SB: Transcriptome profiling identifies HMGA2 as a biomarker of melanoma progression and prognosis. J Invest Dermatol 133: 2585-2592, 2013

20. R Core Team: R: A language and environment for statistical computing. R Foundation for Statistical Computing, Vienna, Austria, 2015

21. Gentleman RC, Carey VJ, Bates DM, Bolstad B, Dettling M, Dudoit S, Ellis B, Gautier L, Ge Y, Gentry J, et al: Bioconductor: Open software development for computational biology and bioinformatics. Genome Biol 5: R80, 2004.

22. Irizarry RA, Hobbs B, Collin F, Beazer-Barclay YD, Antonellis KJ, Scherf U and Speed TP: Exploration, normalization, and summaries of high density oligonucleotide array probe level data. Biostatistics 4: 249-264, 2003.

23. Bolstad BM, Irizarry RA, Astrand M and Speed TP: A comparison of normalization methods for high density oligonucleotide array data based on variance and bias. Bioinformatics 19: 185-193, 2003

24. Smyth GK: Linear models and empirical bayes methods for assessing differential expression in microarray experiments. Stat Appl Genet Mol Biol 3: Article3, 2004.

25. Hoaglin DC, Mosteller F and Tukey JW: Understanding robust and exploratory data analysis. John Wiley \& Sons: pp404-414, 1983.

26. Wickham H: ggplot2: Elegant Graphics for Data Analysis. Springer-Verlag, New York, NY, 2009.

27. Xu J, Liu L, Zheng X, You C and Li Q: Expression and inhibition of ADAMDEC1 in craniopharyngioma cells. Neurol Res 34: 701-706, 2012.

28. Willers J, Häffner A, Zepter K, Storz M, Urosevic M, Burg G and Dummer R: The interferon inhibiting cytokine IK is overexpressed in cutaneous $\mathrm{T}$ cell lymphoma derived tumor cells that fail to upregulate major histocompatibility complex class II upon interferon-gamma stimulation. J Invest Dermatol 116: 874-879, 2001.

29. Han KH, Lee SH, Ha SA, Kim HK, Lee C, Kim DH, Gong KH, Yoo J, Kim S and Kim JW: The functional and structural characterization of a novel oncogene GIG47 involved in the breast tumorigenesis. BMC Cancer 12: 274, 2012.

30. Stefanska B, Cheishvili D, Suderman M, Arakelian A, Huang J, Hallett M, Han ZG, Al-Mahtab M, Akbar SM, Khan WA, et al: Genome-wide study of hypomethylated and induced genes in patients with liver cancer unravels novel anticancer targets. Clin Cancer Res 20: 3118-3132, 2014.

31. Müller M, Beck IM, Gadesmann J, Karschuk N, Paschen A, Proksch E, Djonov V, Reiss K and Sedlacek R: MMP19 is upregulated during melanoma progression and increases invasion of melanoma cells. Mod Pathol 23: 511-521, 2010.

32. Planelles L, Medema JP, Hahne M and Hardenberg G: The expanding role of APRIL in cancer and immunity. Curr Mol Med 8: 829-844, 2008

33. Liu Z, Lu H, Jiang Z, Pastuszyn A and Hu CA: Apolipoprotein 16 , a novel proapoptotic Bcl-2 homology 3-only protein, induces mitochondria-mediated apoptosis in cancer cells. Mol Cancer Res 3: 21-31, 2005.

34. Tang Y, Yan G, Song X, Wu K, Li Z, Yang C, Deng T, Sun Y, $\mathrm{Hu} \mathrm{X}$, Yang C, et al: STIP overexpression confers oncogenic potential to human non-small cell lung cancer cells by regulating cell cycle and apoptosis. J Cell Mol Med 19: 2806-2817, 2015.

35. Park UH, Kang MR, Kim EJ, Kwon YS, Hur W, Yoon SK, Song BJ, Park JH, Hwang JT, Jeong JC, et al: ASXL2 promotes proliferation of breast cancer cells by linking ER $\alpha$ to histone methylation. Oncogene 14: 3742-3752, 2016. 
36. Kraya AA, Piao S, Xu X, Zhang G, Herlyn M, Gimotty P, Levine B, Amaravadi RK and Speicher DW: Identification of secreted proteins that reflect autophagy dynamics within tumor cells. Autophagy 11: 60-74, 2015.

37. Singh S, Singh AP, Sharma B, Owen LB and Singh RK: CXCL8 and its cognate receptors in melanoma progression and metastasis. Future Oncol 6: 111-116, 2010.

38. Cano-Rodríguez D, Campagnoli S, Grandi A, Parri M, Camilli E, Song C, Jin B, Lacombe A, Pierleoni A, Bombaci M, et al: TCTN2: A novel tumor marker with oncogenic properties. Oncotarget 8: 95256-95269, 2017.

39. Tomita T, Ieguchi K, Coin F, Kato Y, Kikuchi H, Oshima Y, Kurata S and Maru Y: ZFC3H1, a zinc finger protein, modulates IL-8 transcription by binding with celastramycin A, a potential immune suppressor. PLoS One 30: e108957, 2014.

40. Singh R, Kapur N, Mir H, Singh N, Lillard JW Jr and Singh S: CXCR6-CXCL16 axis promotes prostate cancer by mediating cytoskeleton rearrangement via Ezrin activation and $\alpha v \beta 3$ integrin clustering. Oncotarget 9: 7343-7353, 2016.

41. Noguchi K, Dalton AC, Howley BV, McCall BJ, Yoshida A, Diehl JA and Howe PH: Interleukin-like EMT inducer regulates partial phenotype switching in MITF-low melanoma cell lines. PLoS One 17: e0177830, 2017

42. Kawahara R, Bollinger JG, Rivera C, Ribeiro AC, Brandão TB, Paes Leme AF and MacCoss MJ: A targeted proteomic strategy for the measurement of oral cancer candidate biomarkers in human saliva. Proteomics 16: 159-173, 2016.

43. Metz C, DögerR, RiquelmeE, Cortés P,Holmes C, Shaughnessy R, Oyanadel C, Grabowski C, González A and Soza A: Galectin-8 promotes migration and proliferation and prevents apoptosis in U87 glioblastoma cells. Biol Res 49: 33, 2016.

44. Mashidori T, Shirataki H, Kamai T, Nakamura F and Yoshida K: Increased alpha-taxilin protein expression is associated with the metastatic and invasive potential of renal cell cancer. Biomed Res 32: 103-110, 2011.

45. Dong W, Gong H, Zhang G, Vuletic S, Albers J, Zhang J, Liang H, Sui Y and Zheng J: Lipoprotein lipase and phospholipid transfer protein overexpression in human glioma cells and their effect on cell growth, apoptosis, and migration. Acta Biochim Biophys Sin (Shanghai) 49: 62-73, 2017.

46. Petroziello J, Yamane A, Westendorf L, Thompson M, McDonagh C, Cerveny C, Law CL, Wahl A and Carter P: Suppression subtractive hybridization and expression profiling identifies a unique set of genes overexpressed in non-small-cell lung cancer. Oncogene 23: 7734-7745, 2004.

47. Li S, Sheng B, Zhao M, Shen Q, Zhu H and Zhu X: The prognostic values of signal transducers activators of transcription family in ovarian cancer. Biosci Rep 37: BSR20170650, 2017.

48. KimKW,PaulP, Qiao J,Lee S and Chung DH: Enhanced autophagy blocks angiogenesis via degradation of gastrin-releasing peptide in neuroblastoma cells. Autophagy 9: 1579-1590, 2013.

49. Chaudhary A, Hilton MB, Seaman S, Haines DC, Stevenson S, Lemotte PK, Tschantz WR, Zhang XM, Saha S, Fleming T and St Croix B: TEM8/ANTXR1 blockade inhibits pathological angiogenesis and potentiates tumoricidal responses against multiple cancer types. Cancer Cell 14: 212-226, 2012.

50. Phan NN, Wang CY, Chen CF, Sun Z, Lai MD and Lin YC: Voltage-gated calcium channels: Novel targets for cancer therapy. Oncol Lett 14: 2059-2074, 2017.

51. Arozarena I, Sanchez-Laorden B, Packer L, Hidalgo-Carcedo C, Hayward R, Viros A, Sahai E and Marais R: Oncogenic BRAF induces melanoma cell invasion by downregulating the cGMP-specific phosphodiesterase PDE5A. Cancer Cell 19: $45-57,2011$

52. Li Q, Qi B, Oka K, Shimakage M, Yoshioka N, Inoue H, Hakura A, Kodama K, Stanbridge EJ and Yutsudo M: Link of a new type of apoptosis-inducing gene ASY/Nogo-B to human cancer. Oncogene 5: 3929-3936, 2001.

53. Safe S, Jin UH, Hedrick E, Reeder A and Lee SO: Minireview: Role of orphan nuclear receptors in cancer and potential as drug targets. Mol Endocrinol 28: 157-172, 2014.

54. Ku AT, Shaver TM, Rao AS, Howard JM, Rodriguez CN, Miao Q, Garcia G, Le D, Yang D, Borowiak M, et al: TCF7L1 promotes skin tumorigenesis independently of $\beta$-catenin through induction of LCN2. Elife 6: e23242, 2017.

55. Girgis AH, Iakovlev VV, Beheshti B, Bayani J, Squire JA, Bui A, Mankaruos M, Youssef Y, Khalil B, Khella H, et al: Multilevel whole-genome analysis reveals candidate biomarkers in clear cell renal cell carcinoma. Cancer Res 15 : 5273-5284, 2012
56. Rasmussen SL, Krarup HB, Sunesen KG, Johansen MB, Stender MT, Pedersen IS, Madsen PH and Thorlacius-Ussing O: Hypermethylated DNA, a circulating biomarker for colorectal cancer detection. PLoS One 12: e0180809, 2017.

57. Goeppert B, Ernst C, Baer C, Roessler S, Renner M, Mehrabi A, Hafezi M, Pathil A, Warth A, Stenzinger A, et al: Cadherin-6 is a putative tumor suppressor and target of epigenetically dysregulated miR-429 in cholangiocarcinoma. Epigenetics 11: 780-790, 2016.

58. Zhao L, Liu Y, Tong D, Qin Y, Yang J, Xue M, Du N, Liu L, Guo B, Hou N, et al: MeCP2 promotes gastric cancer progression through regulating FOXF1/Wnt5a/ $\beta$-Catenin and MYOD1/Caspase-3 signaling pathways. EBioMedicine 16: 87-100, 2017

59. Du HQ, Wang Y, Jiang Y, Wang CH, Zhou T, Liu HY and Xiao H: Silencing of the TPM1 gene induces radioresistance of glioma U251 cells. Oncol Rep 33: 2807-2814, 2015.

60. Camacho Leal Mdel P, Sciortino M, Tornillo G, Colombo S, Defilippi P and Cabodi S: p130Cas/BCAR1 scaffold protein in tissue homeostasis and pathogenesis. Gene 562: 1-7, 2015

61. Gao D, Herman JG and Guo M: The clinical value of aberrant epigenetic changes of DNA damage repair genes in human cancer. Oncotarget 7: 37331-37346, 2016.

62. Zhang Y, Yuan Y, Liang P, Zhang Z, Guo X, Xia L, Zhao Y, Shu XS, Sun S, Ying Y and Cheng Y: Overexpression of a novel candidate oncogene KIF14 correlates with tumor progression and poor prognosis in prostate cancer. Oncotarget 11: 45459-45469, 2017.

63. Yin Y, Liu W and Dai Y: SOCS3 and its role in associated diseases. Hum Immunol 76: 775-780, 2015.

64. Liu G, Xiong D, Xiao R and Huang Z: Prognostic role of fibroblast growth factor receptor 2 in human solid tumors: A systematic review and meta-analysis. Tumour Biol 39: 1010428317707424 , 2017.

65. Chakravarti N, Ivan D, Trinh VA, Glitza IC, Curry JL, Torres-Cabala C, Tetzlaff MT, Bassett RL, Prieto VG and Hwu WJ: High cytotoxic T-lymphocyte-associated antigen 4 and phospho-Akt expression in tumor samples predicts poor clinical outcomes in ipilimumab-treated melanoma patients. Melanoma Res 27: 24-31, 2017.

66. McConnell AT, Ellis R, Pathy B, Plummer R, Lovat PE and O'Boyle G: The prognostic significance and impact of the CXCR4-CXCR7-CXCL12 axis in primary cutaneous melanoma. Br J Dermatol 175: 1210-1220, 2016.

67. Houben R, Hesbacher S, Schmid CP, Kauczok CS, Flohr U, Haferkamp S, Müller CS, Schrama D, Wischhusen J and Becker JC: High-level expression of wild-type p53 in melanoma cells is frequently associated with inactivity in p53 reporter gene assays. PLoS One 6: e22096, 2011.

68. Chang CY, Lin SC, Su WH, Ho CM and Jou YS: Somatic LMCD1 mutations promoted cell migration and tumor metastasis in hepatocellular carcinoma. Oncogene 24: 2640-2652, 2012.

69. Zhou H, Ma H, Wei W, Ji D, Song X, Sun J, Zhang J and Jia L: B4GALT family mediates the multidrug resistance of human leukemia cells by regulating the hedgehog pathway and the expression of p-glycoprotein and multidrug resistance-associated protein 1. Cell Death Dis 4: e654, 2013.

70. Joyce CE, Yanez AG, Mori A, Yoda A, Carroll JS and Novina CD: Differential regulation of the melanoma proteome by eIF4A1 and eIF4E. Cancer Res 1: 613-622, 2017.

71. Huber O and Weiske J: Beta-catenin takes a HIT. Cell Cycle 7: $1326-1331,2008$

72. Udayappan UK and Casey PJ: c-Jun contributes to transcriptional control of GNA12 expression in prostate cancer cells. Molecules 22: E612, 2017

73. Li N, Huang D, Lu N and Luo L: Role of the LKB1/AMPK pathway in tumor invasion and metastasis of cancer cells (Review). Oncol Rep 34: 2821-2826, 2015.

74. Liu J, Fukunaga-Kalabis M, Li L and Herlyn M: Developmental pathways activated in melanocytes and melanoma. Arch Biochem Biophys 1: 13-21, 2014.

75. Mendez P and Ramirez JL: Copy number gains of FGFR1 and $3 \mathrm{q}$ chromosome in squamous cell carcinoma of the lung. Transl Lung Cancer Res 2: 101-111, 2013.

76. Shahi MH, Lorente A and Castresana JS: Hedgehog signalling in medulloblastoma, glioblastoma and neuroblastoma. Oncol Rep 19: 681-688, 2008.

77. Louie MC, Revenko AS, Zou JX, Yao J and Chen HW: Direct control of cell cycle gene expression by proto-oncogene product ACTR, and its autoregulation underlies its transforming activity. Mol Cell Biol 26: 3810-3823, 2006. 
78. Yang B, Zhang S, Wang Z, Yang C, Ouyang W, Zhou F, Zhou Y and Xie C: Deubiquitinase USP9X deubiquitinates $\beta$-catenin and promotes high grade glioma cell growth. Oncotarget 7: 79515-79525, 2016.

79. McDonald SL, Edington HD, Kirkwood JM and Becker D: Expression analysis of genes identified by molecular profiling of VGP melanomas and MGP melanoma-positive lymph nodes. Cancer Biol Ther 3: 110-120, 2004.

80. Hanahan D and Weinberg RA: Hallmarks of cancer: The next generation. Cell 144: 646-674, 2011

81. Ma XH, Piao S, Wang D, McAfee QW, Nathanson KL, Lum JJ, Li LZ and Amaravadi RK: Measurements of tumor cell autophagy predict invasiveness, resistance to chemotherapy, and survival in melanoma. Clin Cancer Res 17: 3478-3489, 2011.

82. Kang HY, Chung E, Lee M, Cho Y and Kang WH: Expression and function of peroxisome proliferator-activated receptors in human melanocytes. Br J Dermatol 150: 462-468, 2004.

83. Botton T, Puissant A, Bahadoran P, Annicotte JS, Fajas L, Ortonne JP, Gozzerino G, Zamoum T, Tartare-Deckert S, Bertolotto C, et al: In vitro and in vivo anti-melanoma effects of ciglitazone. J Invest Dermatol 129: 1208-1218, 2009.

84. Haass NK and Herlyn M: Normal human melanocyte homeostasis as a paradigm for understanding melanoma. J Investig Dermatol Symp Proc 10: 153-163, 2005.

85. Lyons J, Bastian BC and McCormick F: MC1R and cAMP signaling inhibit cdc25B activity and delay cell cycle progression in melanoma cells. Proc Natl Acad Sci USA 110: 13845-13850, 2013.

86. Pierrat MJ, Marsaud V, Mauviel A and Javelaud D: Expression of microphthalmia-associated transcription factor (MITF), which is critical for melanoma progression, is inhibited by both transcription factor GLI2 and transforming growth factor- $\beta$. J Biol Chem 287: 17996-18004, 2012.

87. Nakase H, Uza N, Matsuura $M$ and Chiba T: Importance of CXCL16 as a biomarker for granulocytapheresis in patients with Crohn's disease. Inflamm Bowel Dis 17: 2211-2212, 2011.

88. Shahzad A, Knapp M, Lang I and Köhler G: Interleukin 8 (IL-8)-a universal biomarker? Int Arch Med 3: 11, 2010.

89. Uhlén M, Fagerberg L, Hallström BM, Lindskog C, Oksvold P, Mardinoglu A, Sivertsson Å, Kampf C, Sjöstedt E, Asplund A, et al: Proteomics. Tissue-based map of the human proteome. Science 347: 1260419, 2015.

90. Morse MA: Technology evaluation: Ipilimumab, Medarex/Bristol-Myers Squibb. Curr Opin Mol Ther 7: 588-597, 2005
91. Hathcock KS, Laszlo G, Dickler HB, Bradshaw J, Linsley P and Hodes RJ: Identification of an alternative CTLA-4 ligand costimulatory for T cell activation. Science 262: 905-907, 1993

92. Contardi E, Palmisano GL, Tazzari PL, Martelli AM, Falà F, Fabbi M, Kato T, Lucarelli E, Donati D, Polito L, et al: CTLA-4 is constitutively expressed on tumor cells and can trigger apoptosis upon ligand interaction. Int J Cancer 117: 538-550, 2005.

93. Chen X, Shao Q, Hao S, Zhao Z, Wang Y, Guo X, He Y, Gao W and Mao H: CTLA-4 positive breast cancer cells suppress dendritic cells maturation and function. Oncotarget 8 13703-13715, 2017.

94. Qureshi OS, Zheng Y, Nakamura K, Attridge K, Manzotti C, Schmidt EM, Baker J, Jeffery LE, Kaur S, Briggs Z, et al: Trans-endocytosis of CD80 and CD86: A molecular basis for the cell-extrinsic function of CTLA-4. Science 332: 600-603, 2011.

95. Li F, Zhang R, Li S and Liu J: IDO1: An important immunotherapy target in cancer treatment. Int Immunopharmacol 47 70-77, 2017.

96. Huang PY, Guo SS, Zhang Y, Lu JB, Chen QY, Tang LQ Zhang L, Liu LT, Zhang L and Mai HQ: Tumor CTLA-4 overexpression predicts poor survival in patients with nasopharyngeal carcinoma. Oncotarget 7: 13060-13068, 2016.

97. Zhang XF, Pan K, Weng DS, Chen CL, Wang QJ, Zhao JJ, Pan QZ, Liu Q, Jiang SS, Li YQ, et al: Cytotoxic T lymphocyte antigen-4 expression in esophageal carcinoma: Implications for prognosis. Oncotarget 7: 26670-26679, 2016.

98. Mao H1, Zhang L, Yang Y, Zuo W, Bi Y, Gao W, Deng B, Sun J, Shao Q and Qu X: New insights of CTLA-4 into its biological function in breast cancer. Curr Cancer Drug Targets 10: 728-736, 2010.

99. Ward FJ, Dahal LN, Wijesekera SK, Abdul-Jawad SK, Kaewarpai T, Xu H, Vickers MA and Barker RN: The soluble isoform of CTLA-4 as a regulator of T-cell responses. Eur J Immunol 43: 1274-1285, 2013.

100. Fallarino F, Grohmann U, Hwang KW, Orabona C, Vacca C, Bianchi R, Belladonna ML, Fioretti MC, Alegre ML and Puccetti P: Modulation of tryptophan catabolism by regulatory T cells. Nat Immunol 4: 1206-1212, 2003. 